\title{
Mining and crafting a game to teach research methodology
}

\author{
Carl Marnewick ${ }^{1 *}$ (1) and Jacqui Chetty ${ }^{2}$
}

\section{${ }^{*}$ Correspondence:}

cmarnewick@uj.ac.za

${ }^{1}$ Department of Applied

Information Systems,

University of Johannesburg,

Johannesburg, South Africa

Full list of author information

is available at the end of the

article

\begin{abstract}
Gamification is used in various disciplines to elucidate complex problems. These disciplines are typically the science, technology, engineering, and mathematics disciplines. It is not known whether gamification can be used to teach research methodology. MinecraftEDU was used to create games to explain the various concepts within research methodology. The purpose was to force students to engage with the theory and literature and create a game based on their insights. An analysis of the students' feedback indicates that they preferred this method to more traditional lectures. Although they experienced initial problems with the MinecraftEDU environment, the overall experience was perceived as positive. The results indicate that gamification can be used to teach research methodology, but more research is needed to determine how game elements can be incorporated into a research methodology game.
\end{abstract}

Keywords: Gamification, MinecraftEDU, Research methodology, South Africa, Qualitative, Research onion

\section{Introduction}

"Let the games begin!" This order was given by the emperors of the Olympics in Ancient Greece at the start of the Olympic Games. From this humble beginning, games have evolved and morphed into computer games, online gaming and gamification. The underlying principles of the Olympic games, computer games and gamification are the same with a focus on identity, control and avoidance.

Gamification has been used in various disciplines and fields, especially within the science, technology, engineering, and mathematics (STEM) disciplines. The purpose of gamification is to engage users and solve problems (Ionica \& Leba, 2015). According to Kalogiannakis et al. (2021), gamification "could positively affect students' motivational outcomes, creating positive learning-related attitudes, like engagement, and leading to significant learning achievements".

Based on the results of a bibliometric analysis, it was inferred that research around gamification and the application of gamification is restricted to the STEM and education disciplines. The bibliometric analysis also indicated that little or no research has been done on gamification within the management discipline, specifically research methodology. This article addresses this gap and research was done to determine whether

C The Author(s) 2021. Open Access This article is licensed under a Creative Commons Attribution 4.0 International License, which permits use, sharing, adaptation, distribution and reproduction in any medium or format, as long as you give appropriate credit to the original author(s) and the source, provide a link to the Creative Commons licence, and indicate if changes were made. The images or other third party material in this article are included in the article's Creative Commons licence, unless indicated otherwise in a credit line to the material. If material is not included in the article's Creative Commons licence and your intended use is not permitted by statutory regulation or exceeds the permitted use, you will need to obtain permission directly from the copyright holder. To view a copy of this licence, visit http:// creativecommons.org/licenses/by/4.0/. 
gamification can be used to teach postgraduate students research methodology. Fifty-six postgraduate students created games on MinecraftEDU (Minecraft Education Edition, 2021) and the preliminary results correlate with those of Kalogiannakis et al. (2021).

The layout of the article is as follows: The first section focuses on the literature review. Concepts of gamification and MinecraftEDU are discussed in this section. The second section focuses on the research methodology that was followed, and the coding and thematic analysis of 45 reports. The results analysis is presented in the third section and the results are discussed and interpreted in Sect. 4 . Section 5 concludes the article and some suggestions are made for future research.

\section{Literature review}

Research has shown that students find traditional learning boring, ineffective and dull (Chetty, 2017; Dicheva et al., 2015). As a result, many students remain unmotivated and disengaged (Lee \& Hammer, 2011). To reverse this, novel pedagogies are required to engage students. Some current paradigms available are active learning, collaboration and authentic tasks, allowing students to experience learning in new ways. Teachers and academics within primary, secondary and higher education alike continuously strive to discover innovative ways in which teaching and learning can take place to engage unmotivated students. Therefore, the use of educational games as learning tools has become popular, and the term "gamification" has been coined (Dichev \& Dicheva, 2017; Dicheva et al., 2015; Strayer, 2012; Toda et al., 2019).

\section{Background of gamification}

First documented in a blog post by Terrill (2008) but only adopted in 2010, gamification has been widely employed within a number of domains, such as marketing, healthcare, human resources, training, environmental protection and wellbeing (Dichev \& Dicheva, 2017). From a research perspective, gamification is multidisciplinary with a large knowledge base of both theoretical and empirical data, spanning across multiple platforms and technological realms (Seaborn \& Fels, 2015). However, the primary domain in which gamification is actively explored for research purposes is within the STEM and educational contexts (Toda et al., 2019).

To determine a timeline on the emergence of gamification (Dichev \& Dicheva, 2017; Dicheva et al., 2015) conducted research on emerging practices. Using rigid search criteria, a search was conducted on 7 major scientific databases, such as ACM Digital Library, IEEE Xplore and ScienceDirect. Between 2010 and 2014, the authors extracted only 34 papers where 'gamification', 'gamify' or 'gameful' were the primary keywords used to extract the articles. However, in 2015 gamification gained popularity as the total number of papers rose from 34 to 51 . It is therefore safe to say that gamification, as a discipline, gained popularity within that year. This popularity is evident in the continued growth of research publications as highlighted in Table 1. It also indicates the focus on STEM.

A density visualisation map was drawn based on all the articles pulled from Scopus. Keywords with an occurrence of 20 or higher are displayed. Three major clusters emerged from the density visualisation map. The first cluster focuses on gamification and its various aspects. This cluster is indicated in red. The green cluster focuses on the health and psychological aspects of gamification. The blue cluster, which is also the 
Table 1 Documents per year and by subject area
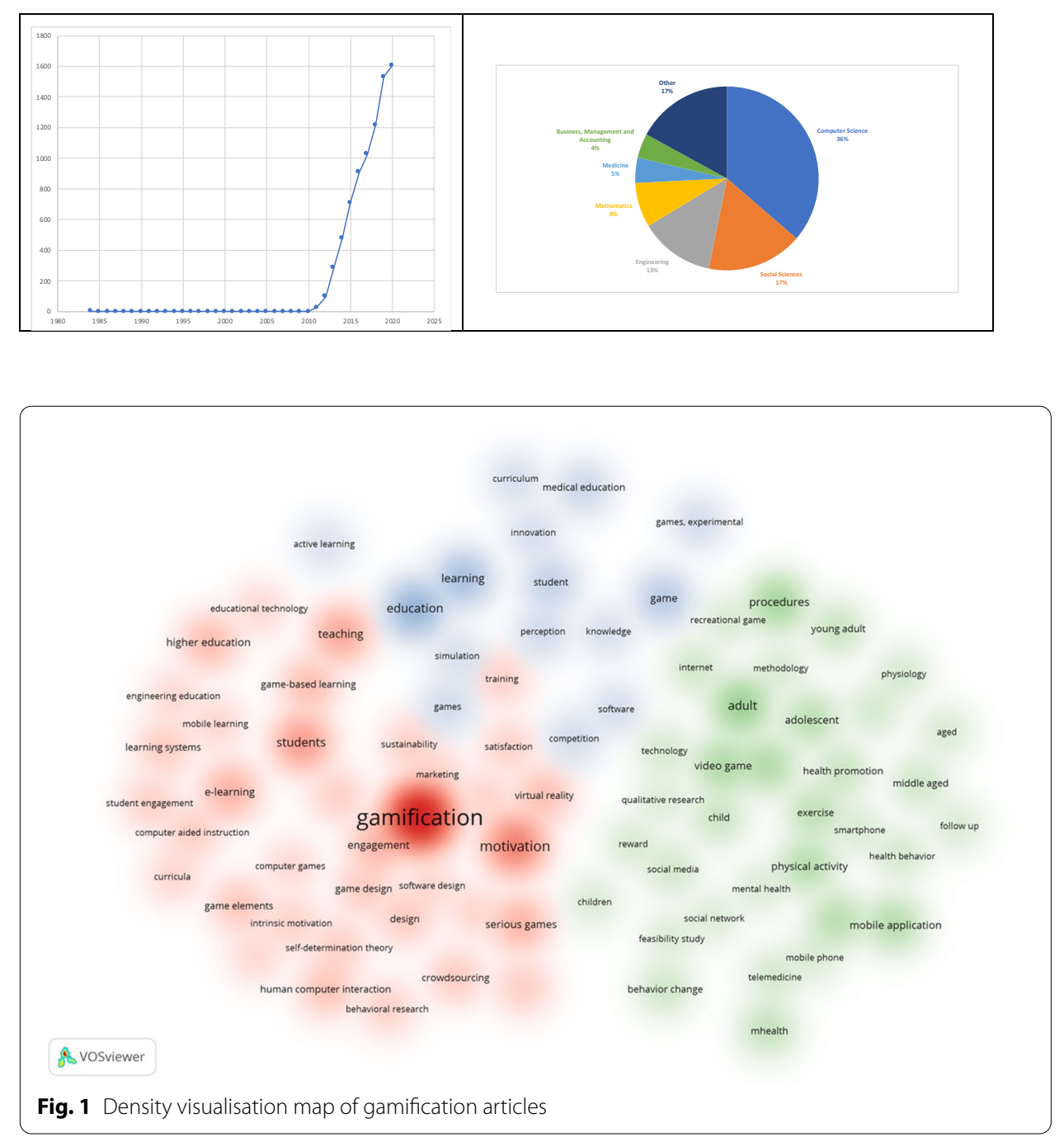

smallest cluster regarding research outputs, focuses on learning, education and the curriculum (Fig. 1).

The proliferation of gamification means that a variety of disciplines have been experimenting with the concept. Within the educational setting, gamification is most used for academic subjects such as Computer Science (CS)/Information Technology (IT), Maths, Multimedia/Communication, Medicine/Biology/Psychology, Languages and others (independent gamified subjects that are not subject reliant) (Dichev \& Dicheva, 2017). However, most of the papers report gamification within the CS or IT discipline. Most of the papers also report that these subjects were targeted within the higher education domain (Dicheva et al., 2015). The types of environmental settings where gamification is applied ranges from courses without online support, MOOCS and online courses, blended learning courses, e-learning sites and gamification support platforms (Dicheva et al., 2015).

Regardless of discipline or environment, gamification makes use of certain principles or gaming elements, also referred to as game mechanics. These include points, badges, 
levels, progress bars and leader boards. According to Dicheva et al. (2015), the game mechanics are categorised into design principles, such as storytelling, goals, customisation and progress. For example, the design principle "progress" is associated with points, levels and virtual goods/currency. Many of the emerging practices from the early years of gamification, such as gaming principles, game mechanics, subject focus, application and education level, still apply today.

As the concept of gamification grew within a variety of disciplines and across environments, taking on a variety of features, the definitions of gamification evolved. Earlier definitions of gamification focused on the creation of games within an educational setting by adding game elements to services (Huotari \& Hamari, 2012). Deterding et al. (2011) describe gamification as the use of game design elements in non-game contexts. Huotari and Hamari (2012) define gamification as the process of enhancing services with motivational affordances (qualities linked to gamefulness) for gaming experiences to support users' overall value creation. Ionica and Leba (2015) use a similar definition and describe gaming as making use of game thinking and game mechanics in a non-game context to engage users and solve problems. Kapp (2012) describes gamification as a toolkit that has the ability to be a powerful and important way in which learning can take place.

The definition of gamification continues to evolve as research around gamification continues to emerge. However, there is still no universally accepted scientific definition of the term (Sailer et al., 2017). The most widely used definition as described by Deterding et al., (2011, p. 5) is summarised as follows: "the use of design (rather than gamebased technology or other game-related practices) elements (rather than fully developed games) characteristic for games (rather than play or playfulness) in non-game contexts (regardless of specific usage intentions, contexts, or implementation media)". The four main components are game, elements, design and non-game context.

For this study, gamification provided students with a platform on which game thinking was incorporated to create a gaming experience in a non-gaming context. The aim was to use gaming principles and game design elements to create a real-world application that motivated students and encouraged learning using aspects of games-fun, play and challenge-to support their understanding of abstract concepts better (research onion of Saunders et al., 2016) within a higher education institution.

\section{Gamification approaches}

Although gamification in the general sense is the use of a game in a non-game context, there are other styles or approaches to gamification, namely serious games and simulation.

Serious games are games that are designed for purposes other than just entertainment. These are fully fledged games (Brathwaite \& Schreiber, 2009) and serve a very specific non-entertainment purpose (Deterding et al., 2011). The term 'serious' refers to the use of products by industries such as defence, education, scientific exploration and healthcare, to name a few (Smeaton, 2017).

Simulation, on the other hand, is described as the imitation of the operation of a realworld process or system over time (Ionica \& Leba, 2015). When something is simulated, it means that a model of what is to be simulated needs to be developed. The model 
represents everything that the physical or abstract system is (characteristics) and the simulation represents everything the system does (behaviours).

Regardless of the approach taken, gamification applications rely on the notion of gameful elements, the building blocks on which the application is built.

\section{Gameful elements}

There is a distinct difference when it comes to gamification related to games and that of play or playfulness (Salen \& Zimmerman, 2004). Deterding et al. (2011) distinguish between the different terminology associated with gamification, in particular the link between paidia and ludus, also known as the Caillois concept (Caillois, 2001). Paidia is associated with free play, where explicit rules do not apply. For example, a child playing out a fantasy game, where the only implicit rules would apply within the context of their socio-cultural context, shows a paidic form of play (Jensen, 2013).

Within the context of gamification, paidia often translates into ludus, which is a structured, rules-based competitive form of play with distinct goals and outcomes. Ludus focuses on design elements for rule-bound (explicit), goal-oriented play, with little focus on play. The importance of ludus within the gamification context lies in that it provides researchers with a valuable opportunity to observe gaming experiences and behaviours, thus providing empirical data on the design and experience of systems in a rule-bound context (Deterding et al., 2011). The idea is to incorporate the notion of games and playfulness as gamefulness. For this study gamefulness or ludus was based on gameful interaction.

The aim of gamification is to provide a platform, through applications and processes, to improve engagement and learning. This is accomplished by providing rewards for players who accomplish tasks (Flatla et al., 2011; Juul, 2011). The use of badges and challenges provides a platform for social engagement. To further incentivise, these rewards are made visible to others to increase competitiveness (Lee \& Hammer, 2011). To produce an enjoyable game that keeps a player motivated, game mechanics constructs with rules and feedback loops must be included.

Game mechanics form the foundation on which gamification is built (Deterding et al., 2011; Sailer et al., 2017; Toda et al., 2019). According to Kumar and Herger (2013), game mechanics are the most visible part of gamification. They become the constructs that make up the rules and feedback loops intended to produce enjoyable gameplay. As building blocks, they can then be applied and combined to gamify any non-game context. The term 'game mechanics' represents the broad, abstract view that depicts the artistic vision and talent creators of a game. Game mechanics focus on strategy, mission and motivation drivers and their implementation is achieved through the physical implementation of game elements or curated lists. The terms 'game mechanics' and 'game elements' are often used interchangeably (Kumar \& Herger, 2013).

Points, badges, leader boards, relationships, challenges, constraints, journey, narrative and emotion are some of the gameful elements that can be used to create a game (Kumar \& Herger, 2013). These are the game mechanics in action that form the foundation on which the game constructs, rules and feedback mechanisms are built. A player can earn points and, once a certain number of points have been accumulated, badges are then awarded. This in turn motivates players to earn more points and collect more badges. 
This then catapults a player onto the leader board. It can be demotivating if a player finds themselves at the bottom of the leader board, but it can also motivate a player to get more points and move up the leader board. Ultimately, this can then lead players to connect with other players. As a society, many people are social beings and community driven.

Although some researchers refer to the building blocks of gamification as game mechanics, Reeves and Read (2009) identified a set of "ten ingredients of great games", including avatars, narrative, context, feedback, competition and teams. Toda et al. (2019) created a taxonomy of 21 game elements for gamification. These elements relate to concepts such as acknowledgement where authors of games include praise for players when they get specific actions correct. This could be in the form of badges or trophies. Further elements relate to storytelling, competition, time pressure, puzzle completion and levels, to name a few. Other authors have also proposed a variety of game design elements (Kapp, 2012; Robinson \& Bellotti, 2013). Sailer et al. (2017) selected specific game elements from the exhaustive list identified by a body of literature to address the effects of game elements from a psychological perspective. The selected game elements are points, badges, leader boards, performance graphs, meaningful stories (narratives), avatars and teammates.

Regardless of the building blocks on which a game is designed, consideration needs to be given to the game plan. This can be achieved through the inclusion of a game economy, game rules and engagement loops (Kumar \& Herger, 2013). Game economy refers to tokens of different currencies that can be applied to increase motivation-implemented through game elements such as points, badges and leader boards. Burke (2014) describes game economy using key terms such as self-esteem, fun, social capital and things. For example, self-esteem can include leadership, conquest, mastery, access or praise. A player achieves this through the inclusion of levels or badges. Game rules follow game mechanics or game elements. In other words, to achieve points or badges the player needs to follow a particular set of rules-rewards for certain actions. For example, if a player gets to level 2, they earn a badge; therefore those rules of engagement would apply for a player to earn a badge. Together, the game mechanics and the rules motivate a player to achieve a mission. The engagement loop refers to motivating players to keep them engaged and re-engaged, and to provide feedback and reward.

Game mechanics are the visible aspect of gamification and most probably one of the foundational constructs on which a game is built. For this study, games were designed, planned, constructed and implemented using Minecraft.

\section{Minecraft}

Minecraft is one of the most popular games in the United States with over 100 million registered users (Junco, 2014) and it is the third most successful video game ever released (Gershenfeld, 2014). It promotes creativity and learning in an unconventional educational way (Ellison et al., 2016). Minecraft is seen not simply as a video game, but has become a powerful educational tool, used as a vehicle for teaching critical content in a more engaging manner (Callaghan, 2016; Ellison et al., 2016; Gershenfeld, 2014; Smeaton, 2017). 
Minecraft is quite different from other games in that it provides a digital "sandbox" and video game that allows individuals to freely create and manipulate their own simulated worlds (Ellison et al., 2016; Smeaton, 2017). It also does not have any tutorial level, instructions or hints to guide a player. Minecraft forces the player to discover the environment and individuals can design games in a way that gives them full control of what they have created. Another way in which it is unconventional is that there is no sense of purpose, such as an objective of a high score or the objective to escape, and there is no ending (Callaghan, 2016; Smeaton, 2017).

Minecraft can be defined as a Java-based first-person multiplayer sandbox game (Ekaputra et al., 2013), where blocks are placed in a grid-like matrix, similar to a virtual Lego. Players can manipulate every element within the Minecraft world, excluding the bedrock (the bottom-most layer). They can choose either adventure where they travel through the world fighting enemies, hunting, gathering, surviving and exploring, or they can choose construction or terraformation-the process of creating an Earth-like or habitable environment that resembles a planet where the players transform their surroundings, creating structures (Smeaton, 2017).

\section{Minecraft and student-centred learning}

Minecraft provides an opportunity to teach students and promote learning within an environment where the key elements of learning are enjoyment, fun, motivation and engagement. Student-centred learning (SCL) is an umbrella term to describe a learning environment where students are actively engaged in their learning, and one in which teachers become facilitators of the learning (Hoidn, 2017) as opposed to students being passive listeners. SCL provides a learning perspective where the teaching is unidirectional, and students acquire a deeper level of learning within an autonomous environment where the learning is their responsibility (Arman, 2018; O'Neill \& McMahon, 2005). Parellels can be drawn between SCL and Minecraft as students develop Minecraft projects where active learning, problem solving, deep learning, collaboration, reflective thinking and student responsibility are fundamentals associated with learning within a Minecraft environment. Within the context of this study, the goal was to deliver an SCL approach to students learning about research methodology.

\section{MinecraftEDU}

Gershenfeld (2014) envisages that games will have a deep impact on learning when they become a meaningful part of the educational experience. MinecraftEDU is a specialised build of Minecraft aimed at providing educators with more control and flexibility when using Minecraft as an education tool. By using the Minecraftedu.com platform, students are able to actively learn about a number of content areas, such as science, maths, history, engineering and computer coding (Ellison et al., 2016). The creators of the games are critical content creators, and the Minecraft platform provides an education tool. Individuals that play the created games become active learners and the gaming environment enhances their motivation to learn (Hwang et al., 2019).

MinecraftEDU can provide numerous benefits that should be highlighted, as the notion of video games within a classroom setting is often misunderstood by stakeholders such as teachers, parents and administrators (Ellison et al., 2016). Hollett and Ehret 
(2015) describe playing Minecraft as reshaping the "social, relational space". Students do not play games for personal gratitude but share their experience with others (Cohen, 2014). This has led to the general use of massive multiplayer online role playing games (MMORPGs) (Fuster et al., 2014) where students collaborate with one another and use their different skill sets to complete a challenge (Cole \& Griffiths, 2007). The inclusion of cooperative learning provides the opportunity for students to utilise one another's unique skill sets, thus promoting learning and collaboration between students.

Today's students process information in several different ways. Minecraft provides a platform that goes beyond words, where images, music and sounds embody movement and interaction (Streeck et al., 2011). The limited use of written language transcends any language barrier, replaced with graphics, images, symbols and "visuospatial reasoning skills" (Junco, 2014). By illuminating this barrier, students that are not first-language speakers may have a better opportunity to create a virtual world, as the learning is not dependent on language. This is often the case in a country like South Africa where there are 11 official languages.

Not only does Minecraft transcend learning styles and language, but it also provides an ideal opportunity for students to learn collaboratively. Sáez-López et al. (2015) conducted a study of middle school learners to analyse motivational, learning and engagement levels when playing Minecraft. These learners appreciated the use of Minecraft as part of their curriculum and felt that it gave them an opportunity to feel in control and be active participants, protagonists and creators in their virtual worlds. The results indicate that Minecraft increased their creativity and learning (Sáez-López et al., 2015). This approach is similar to problem-based learning (Smeaton, 2017) where real-world problems or scenarios are placed within a framework of 'playing' to learn (Ebner \& Holzinger, 2007). Games, such as MinecraftEDU include many characteristics of problem solving. For example, students that are presented with a real-world problem to solve have no idea what the outcome may be, have multiple paths that could lead to the goal and need to construct a problem context.

MinecraftEDU offers the opportunity for a collaborative learning environment where participants share information and learn from one another (Felicia, 2009). Students can construct knowledge and engage in authentic task practices, thus providing opportunities for students to learn outside the boundaries of a classroom. It shapes pedagogy, where students can collaborate within a particular content area to encourage authentic tasks (Williamson, 2009). This provides an opportunity for assessment to take place in an innovative way.

Using MinecraftEDU as a pedagogical gamification tool promotes active learning and problem solving of complex tasks, all of which would be difficult to recreate in the real world. These skills are mapped not only to SCL, problem-based learning and collaborative teaching, but also relate to the higher order thinking skills (HOTS) of Bloom's taxonomy - an imperative set of skills required if students are going to be extending their knowledge base substantially (Mishra \& Kotecha, 2015). The HOTS used when creating a Minecraft game relate to application, analysis, evaluation and creation. For example, students presented with problems to solve using MinecraftEDU are expected to create a new "world" within the MinecraftEDU environment. They have to design, build, construct and plan, all essential HOTS. They must evaluate the decisions they make by 
critically examining the information they have at hand to make judgements, and constantly critique, defend and criticise their choice of construction and inclusion of game elements. They also need to analyse their developing product by examining, comparing, contrasting and organising their construction in such a way that it makes sense to others.

In summary, MinecraftEDU gamification projects provide a platform on which to build teaching and learning that promote student-centred learning, collaboration, authentic tasks and innovative assessment (Han et al., 2015), all valuable twenty-first century pedagogical approaches. There is no doubt that gamification is an important and powerful tool that can shape industries alike, education included. However, there is still doubt surrounding the legitimacy of gaming in education and research is ongoing (Callaghan, 2016). The accumulation of research papers may shape the legitimacy of gamification. However, more evidence is required to determine whether gamification can be a serious educational contender for teaching and learning to thrive. Consequently, the research problem within the context of this study focused on students constructing a Minecraft world that contributed to students' learning of the research onion of Saunders et al. (2016). The main objective was to understand the different decisions and associated consequences when developing a research methodology through the application of gamification principles. Without understanding the relationships between the various layers of the research onion, it would be problematic for students to create a game that depicted such layers.

\section{Research methodology}

\section{Case description}

Students enrolled for an honour's qualification in information technology. Within this qualification, they need to master a module named Research Methodology. This module covers aspects of the research process, from identifying and defining a research problem, performing a literature survey, conducting the research, to analysing and publishing the results. The research onion of Saunders et al. (2016) is used to facilitate the learning process. The number of enrolled students increased from 34 in 2015 to 56 in 2020 . The progress of the students is shown in Fig. 2. The average final mark increased from $53 \%$ in 2015 to $69 \%$ in 2020 .

Up to 2019, the content was explained to the students in formal lectures and assignments were of a practical nature. The concepts of the research onion had to be applied to the students' research project. In 2020, an additional assignment was introduced focusing on gamification. The assignment read as follows: Create a game within Microsoft Minecraft to explain the research onion of Saunders et al. (2016). The aim of the assignment was to engage students with the theoretical knowledge of research while developing a game. The focus was on creating a game, thus incorporating theory and knowledge, and not learning research methodology by playing the game. The students were given two opportunities to submit their game. After the first opportunity, feedback was given on the game itself. The focus was on the ease of play, the level of difficulty and the inclusion of gameful elements. The feedback also covered the research methodology content, and the aim was to determine whether the content was appropriately covered in the game. The students could then incorporate the feedback into their games and enhance the gaming experience. The final 


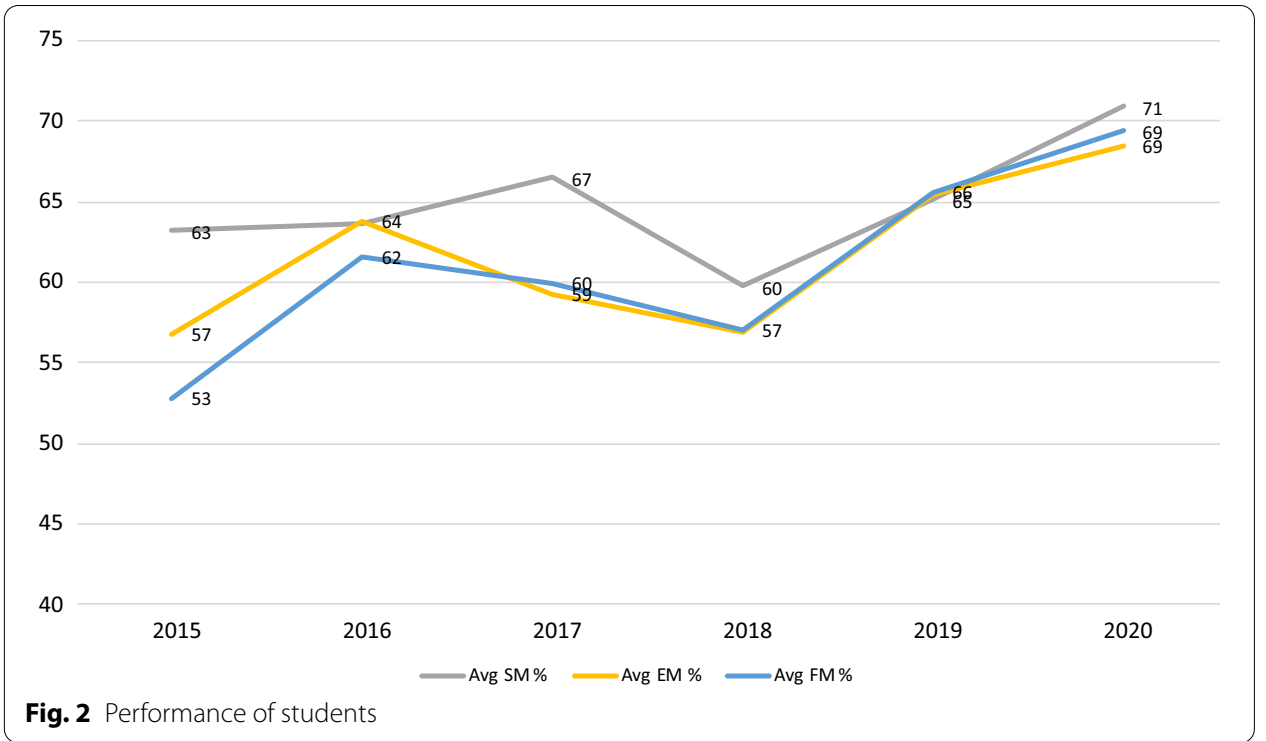

Table 2 Results of gamification attempts

\begin{tabular}{lcc}
\hline & First attempt & Final attempt \\
\hline Mean & 53.34 & 69.47 \\
Std. deviation & 17.131 & 11.735 \\
Skewness & -0.757 & -1.123 \\
Std. error of skewness & 0.369 & 0.327 \\
\hline
\end{tabular}

game was then submitted for a final assessment. The results in Table 2 highlight the improvement from the first attempt to the final attempt. The average improved by $16 \%$ indicating that learning took place at two levels i.e., (1) incorporating gameful elements and (2) mastering of the research onion. There was also a positive correlation between the marks $(r=0.336, p=0.032)$.

At the end of the semester, the students were required to reflect on their experience, focusing on the following two aspects:

1. In the Minecraft section, the following had to be covered: challenges that they had, future lessons for other students, whether it was fun, how they could improve and whether they thought they could learn research methodology through a welldesigned game.

2. In the research methodology section, the following had to be covered: whether they learnt more about the research onion as part of the game design, whether they preferred this method to a more formal report and whether they could link the contents of the game to their own Research Methodology assignment.

These reports formed the basis of this article and were used for analysis purposes. 
Table 3 Code saturation

\begin{tabular}{llll}
\hline Document \# & Number of codes & \# of new codes & Total \\
\hline 1 & 0 & 21 & 21 \\
2 & 21 & 17 & 38 \\
3 & 38 & 11 & 49 \\
4 & 49 & 7 & 56 \\
5 & 55 & 8 & 63 \\
6 & 63 & 6 & 69 \\
7 & 69 & 0 & 69 \\
8 & 69 & 2 & 71 \\
9 & 71 & 0 & 71 \\
10 & 71 & 0 & 71 \\
\hline
\end{tabular}

Table 4 Themes and number of associated codes

\begin{tabular}{lc}
\hline Theme & $\begin{array}{c}\text { Number } \\
\text { of codes }\end{array}$ \\
\hline Aid (Additional support) & 6 \\
Benefits & 5 \\
Challenges & 18 \\
Experience & 3 \\
Future lessons & 10 \\
Game learning & 11 \\
Minecraft & 5 \\
RM learning & 13 \\
\hline
\end{tabular}

\section{Coding}

Forty-five reports were received from the group of 56 students. These reports were made anonymous and then loaded into Atlas.ti to analyse their reflections (Lewins \& Silver, 2008). Atlas.ti enables researchers to code documents for analysis purposes. These codes allow researchers to test the relationship between issues, concepts and themes and to develop broader or higher order categories (Saldana, 2013; Silverman, 2017). They also facilitate the development of a detailed understanding of the phenomena which the data is seen to be presenting (Saldana, 2013). The researchers used open coding to prevent bias towards any predefined areas of interest and a final list of 71 codes was extracted. Saturation was reached after the eighth report as indicated in Table 3.

The reflective assignment was used as guidance for the themes as per Table 4 .

\section{Data analysis and interpretation}

\section{Benefits}

The students experienced the exercise as beneficial to them. One benefit was that the students experienced it as engaging and fun. Student-28 emphasised the fun aspect: "The game it was fun you get to feel you in your own real world." Student-1 mentioned that "it was a little fun and engaging". Another benefit as highlighted by Student-4 was that it "[forced] them to think outside the box, and create a flexible learning environment". 
Another benefit was the acquisition of new skills:

- "However I did gain some problem solving skills, planning and analytical and critical thinking skills within the game, mostly researching skills because with everything being done with the game I had to first do some research on what other Minecraft users have done in order to apply it on the game." [Student-2]

- "Minecraft is customizable, it's an extremely versatile game, with tools that allow you to adapt it to the skills of your choosing and the way you want to play and learn, it's a game that can evolve with the gamer when they become more skilled and experienced." [Student-29]

In a developing country such as South Africa Internet access and bandwidth are problematic for some students. Student-1 mentioned that "the nice thing about the game is you can play it offline". This made the students less reliant on the Internet.

\section{Additional support}

Creating a game was a new experience for most of the students and they had to apply a variety of innovative ways to master the Minecraft environment. The most popular aids were YouTube tutorials and videos.

Student-3 mentioned that "I had to do self-learning by viewing existing games on YouTube and see how it is done". This sentiment was echoed by other students:

- "With the aid of YouTube, I was introduced to a new mode of the game where I had an unlimited supply of resources. This brought about a great deal of relief as I had spent days collecting resources. I had began to lose hope on where I was headed with the game. I continued to rely on tutorial videos to assist me in coming about to reach my objectives." [Student-2]

- "The use of YouTube can help students to see some very much interesting concepts that come with the game and as well just to enhance their creativity levels by seeing how other students will be doing it." [Student-6]

However, the use of YouTube tutorials and videos did not assist some students. Student- 4 and Student-7 echoed each other stating, "I did not have a clue how I was going to start, watched several videos and was still clueless" and "I watched many YouTube videos and took some of the tutorials on Minecraft and was still clueless".

This feeling of 'I am lost' by some students was overcome by asking other students for assistance. "I had to ask team members and search to get me going" [Student-1]. Student- 4 decided that an alternative way was to get their hands dirty by "start building a house and my creativity adjusted as I put the bricks in place to build walls".

\section{Challenges}

The students faced numerous challenges at the beginning of the assignment. These challenges are highlighted in Fig. 3. The linkage between the various challenges is also indicated. 


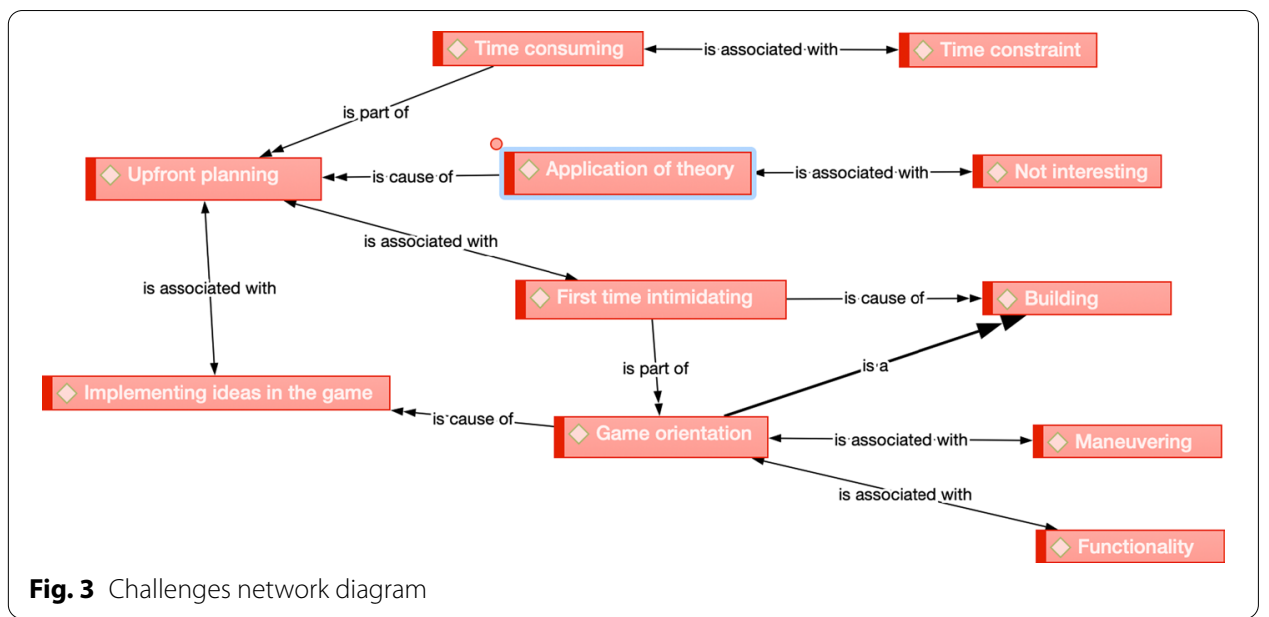

The first challenge that the students faced was the upfront planning and how to create a game around research methodology. "Since I had no prior knowledge of using the game, let alone how it worked or what the objectives of the game were, I found myself lost in thought as to what I would actually be doing with such a platform" [Student-8]. "A lot of planning and thinking goes into what you want to build and see come alive in the game" [Student-1]. The challenge was to match the content with a gaming strategy and then to implement it into a Minecraft game.

The first theme was around the Minecraft environment. The students found the Minecraft environment intimidating the first time around, which was a direct cause of building the game. Because the students were not comfortable with the environment at first, they experienced challenges in the construction of the game. "Also just finding the starting point was an issue for me, I did not know where to even begin the game which world to pick to start the game" [Student-6]. This was echoed by Student-20 stating that, "For a first-time user of a game/gaming platform it was very intimidating". This is associated with the game orientation itself, how to manoeuvre within the game and what controls to use to move around and build the game. "Making a small mistake with the NPC meant that I have to delete that NPC and create a new one with new code and instruction" [Student-5]. The entire theme can be summarised in the words of Student-12: "I had a couple of challenges but the biggest challenge that I faced was learning how to use many of the different functions available in Minecraft as I have never played Minecraft before and this took quite a lot of time before I was able to start creating and being creative with my game."

The second theme was that the students found it challenging to apply the theory to a game and to convert the theory into gaming principles and specifically Minecraft functionality. "One of the challenges was interpreting and presenting the requirement of the assignment in a form of a game" [Student-28]. The comment was also made that it was not interesting at all to create a game: "In the beginning, I found Minecraft less interesting and didn't understand how to apply the research methodology content to a building a game on Minecraft" [Student-4].

The third theme relates to the time spent on the game. The students perceived it as time consuming to construct an engaging game. This must be seen against the 
background that some of the students were part time and did not have too much time to focus on their studies.

"I could not use the Minecraft on my spare time and I prefer to work at night" [Student-3] and "Time constraints while building the game was a challenge, I believe If I have invested most of my time in building this research I would have created a more unique and creative game with more feature on assisting in understanding the method and have fun at the same time" [Student-33].

\section{Future lessons}

Suggestions and future lessons arose from the challenges as depicted in Fig. 4. The overarching theme is that training should be provided to the students before they start the assignment.

Student-37 suggested, "I would highly recommend training for the game and to have tailored learning lessons created by the lesson givers for the game so that students have a guided introduction on the game". Other suggestions included "The lecturer could have an activity in class where the class familiarizes themselves with Minecraft education" [Student-15] and "... is for Minecraft workshops to be provided to students at the beginning of the semester if this approach is to be used in the future" [Student-7].

Some suggestions not related to the Minecraft environment focused on the planning of the game.

- "Students should first write down a document of how they would like the game to be because it's easy to lose the plot as you start building your game." [Student-25]

- "Another advice is that students should never just start a game freestyling without proper planning, the game will end up meaningless and confusing." [Student-36]

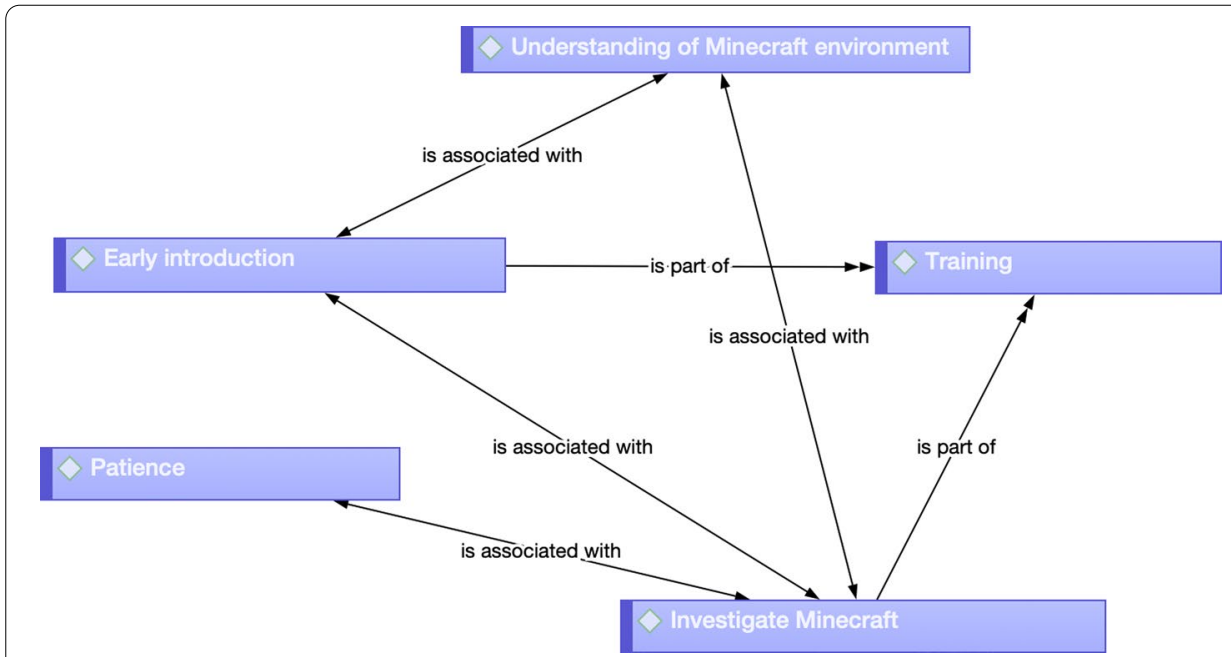

Fig. 4 Future lessons network diagram 


\section{Game learning}

The students were asked to reflect on their experience with regard to gaming as a means to learn. Of the 45 students, only four students indicated that they did not see gaming as a way to learn. "No, it is disturbing when you trying to learn and understand concepts and trying to figure out how the game works in the first place" [Student-1] and "No, I prefer a formal report compared to this method" [Student-38] (Fig. 5).

The students that found game learning to be a positive experience mentioned the following benefits:

- "Creating the game truly challenges you mentally because the assignment question is so broad, as you start researching the different worlds you then struggle to create the perfect game that will meet the assignment requirements." [Student-35]

- "The game version stimulates the brain and increases mental cognition compared to the formal report where the brain often gets tired while reading the stuff which can make you miss vital information." [Student-26]

- "Making a game while learning was the really fun part for me." [Student-19]

Some of the students believed that deep learning took place as "interaction" [Student-16] and "It gives me a more in-depth understanding since the goal is to learn at the end of the game" [Student-23].

Gaming as a learning aid was summarised by Student-32: "While I was designing the game I became more of a critical thinker and a problem solver since I uncovered certain patterns as to how I can best approach my research."

The aim of introducing gaming and specifically Minecraft as a learning tool was to determine whether students would more easily master the various concepts of research methodology such as paradigms and approaches.

\section{Learning of research methodology}

Student-43 mentioned, "Yes this is a very interactive way of performing research. Depending on the game structure, I think all the levels of the research onion can be portrayed and the differences understandable." This was the overwhelming sentiment when the students' reflections were analysed (Fig. 6).

Three main themes emerged from the analysis. The first theme emphasises the incorporation of theory into gaming. "I can suggest research methodology to be taught in a well-designed game, I believe that will help student to not forget the logic

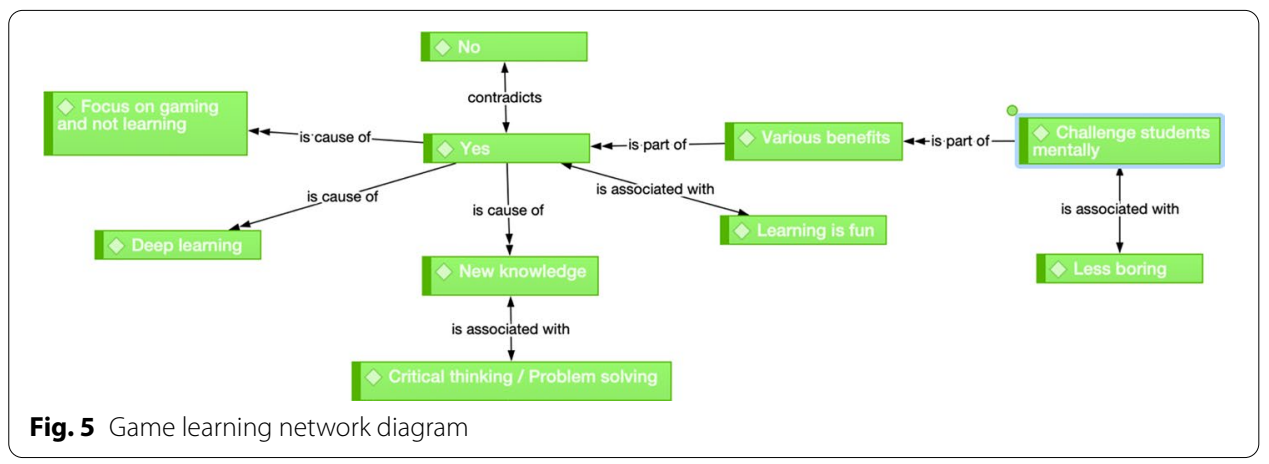




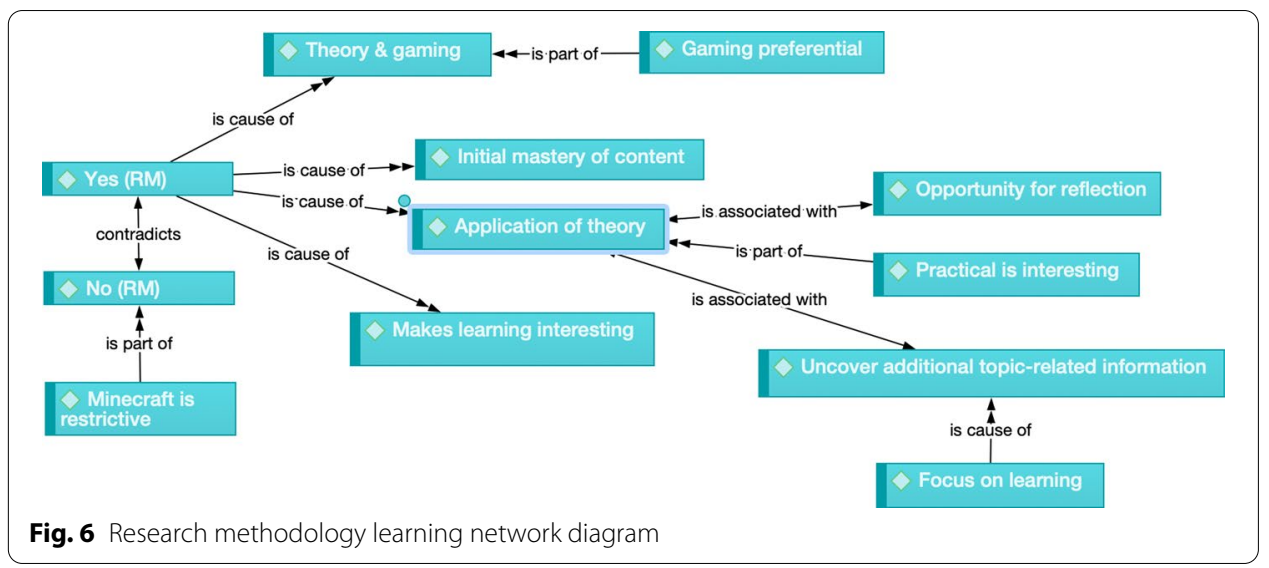

around it and have fun while learning the flow of the research onion" [Student-23]. This view was supported by Student-5 stating, "using Minecraft instead of a formal report is a better method because you get to have fun and let your creativity skills run wild while integrating the research methodology information with Minecraft". Student-42 preferred learning research methodology through gaming "because people understand things differently some prefer technical way as it helps you to acquire the specific techniques that become the tools of your trade and understand it better when hands on". Student-34 preferred "learning the research methodology through the game more than a formal report because it makes me acquire and retain more information".

The second theme revolves around the notion that the content first needs to be mastered before it can be applied to game design. "A well-designed game can give students a good outline of what research methodology is but students will still need other academic sources to get a comprehensive lesson on research methodology" [Student-9]. This was echoed by Student-29 and Student-41: "the game also forced me to breakdown each component of the onion into levels and that helped me learn more" and "I needed to understand and know the onion first to be able to even think of incorporating it in the game".

The third theme addresses the application of the theory itself. This should be read in the same context as the second theme. Student-10 made the following comment: "While making the Minecraft Education edition game, it helped me to relook at the different approaches I may use for my research assignment. It helped me redefine and have through research done for my research problem." Through the construction of the game, the student enhanced his own research report and therefore improved the success of the research project. This sentiment was echoed by Student- 6 , who stated that "also I learned a lot from the research onion in the process of building my own game which then helped me to create a better research methodology for my project". This theme was summarised by Student-4 stating that "I now have a better understanding of Saunders' research methodology and other concepts related to conducting research. The learning aspect of it has increased my abilities to construct a research methodology for my research project". 


\section{Reflection on MinecraftEDU}

Ellison et al., (2016, p. 26) state that Minecraft "promotes creativity and learning in ways that would afford more educational benefits for students". This section of the data analysis focuses on the students' perception of Minecraft per se as a teaching and learning tool. The students used various features within the application to assist them in the construction of their games. "With a built-in feature of inviting others to a space I had created was an interesting feature to have access to" [Student-2]. Other students went even further and used the programming aspect to enhance their games. "I used commands to execute certain functionalities, for example, '/teleport @ $p 012$ ' is a command to teleport players from their current location to the coordinates 012 in my world" [Student-4].

The functionality of the application was encouraging as well as restrictive. Student-30 experienced frustration with copying and pasting content. "Copy and paste were not available on the game, for instance, when I was putting up boards. I could not copy work from a document straight into the board the way I wanted, highlighting, cutting and deleting specific text was also a problem." The different modes in the game enabled the students to determine the kind of game they wanted to develop. "Students must explore and understand the different game modes (Survival, Creative etc.) as this will help them understand what kind of game they are going build" [Student-9]. Student-40 mentioned that the templates made it easier to build a game. "Students must understand what worlds (in the game) are and must understand how to create a world or select a world that has already been created (template)." Student-29 said, "I had to browse through, and inspect different array of game templates that could serve the overmentioned objective well. I ended up reverting to the Labyrinth game structure."

The students also perceived the application as user-friendly.

- "The game's platform of access is very user friendly. From the get go, I was able to sign in, not only in the classroom but remotely as well." [Student-2]

- "Overall, the game is a user-friendly environment and platform. Users and/or learners can quickly learn difficult concepts, simply by following the game, reading the signs and boards provided and following the instructions." [Student-28]

- "Minecraft is a user-friendly environment (once you get a hang of it) and it allows users to increase their creative abilities." [Student-37]

The students also felt that the application gave them freedom to implement their ideas and imagination. "You can build whatever you can imagine with this game. The game will challenge your creativity" [Student-35]. This sentiment was echoed by Student-27: "Minecraft gives an understanding to be creative and build according to your imagination."

\section{Discussion}

The results of the study indicate that students benefited from gamification insomuch as they found it fun to create and implement a game, based on the learning taking place within the classroom setting. The goal of gamification is to include the enjoyable 
aspects of games, such as fun (Dale, 2014), and apply them to modules found within higher education.

The use of Minecraft as a pedagogical tool is of particular importance within the context of this study. The results indicate that students were required to "think outside the box" and apply problem-solving skills as well as analytical and critical thinking skills. This is consistent with the theoretical considerations of SCL, a well-known pedagogical approach for students to become actively engaged, and educators to design and facilitate the learning process so that learning is about exploration, retaining ideas and creating innovative projects. The aim of SCL is for students to experience, collaborate, test, create and direct their own learning (O'Neill \& McMahon, 2005). Within this study, students created a game using Minecraft by translating theory into game design principles and ultimately a working game that had to be tested.

Students within the context of this study found the learning outside of their comfort zone, thus providing the potential for learning to develop that embraced qualities of SCL, namely active, deep learning that is self-directed and independent. For example, students were presented with a project where, at times, they had no idea where to start, and they had to think outside the box to connect the theoretical constructs of research methodology to resemble a Minecraft game. Many students reflected on their experiences by including terms such as in-depth understanding, critical thinking and problem solving. Developing a game using Minecraft gave students an opportunity to inhabit SCL and therefore HOTS.

Students struggled to take the theory, i.e., the research onion of Saunders et al. (2016) and layer it within the context of gamification. Within the realm of SCL, one of the main qualities of such learning is providing an opportunity for students to extrapolate the theory into a practical implementation. Students who achieve this often develop a deeper understanding of the theoretical constructs. For example, students stated that taking the research methodology content and creating a game from it was overwhelming, and they had no idea where to start. Other students stated that the research methodology topic was very broad and again they had no idea where to begin. Mastering of the theory was evident in the student's final report that they submitted. There was a weak positive correlation between the mark that the students' received for the game and the final research methodology report $(r=0.271, p=0.049)$. This does indicate to a certain extent that the creation of the game assisted the students to master the research methodology concepts and incorporate it into a final report.

Motivation and participation are important drivers for SCL (Trinidad, 2020). Similarly, motivation is also the primary benefit of teaching and learning within a Minecraft setting (Sáez-López et al., 2015). The enthusiasm of the students within this study was reflected through their interpretation of the experience-the assignment was fun, engaging and gave them an opportunity to create their own learning within a context of their choosing. Motivation is also about the importance of the class collective engagement (Trinidad, 2020). Students collaborated with each other and noted first-hand how other students were engaging with Minecraft, they formed discussion groups and learnt skills from each other.

MinecraftEDU provided a supportive environment in which learning could take place. When students reflected on the MinecraftEDU platform, they were encouraged by its 
ease of use, user-friendly instructions as well as templates. As stated by one student, this user-friendly environment provided a learning foundation on which their creative abilities could grow. However, there were many students that found the platform intimidating, frustrating and restrictive. Students stated that the simple notion of copy/paste was not an available option, so they had to "think out of the box" when circumnavigating certain tasks. This is not necessarily counterproductive as it forces students to think differently about how tasks are to be completed.

On reflection, the lecturers teaching the module had little expertise in gamification. This could be an advantage in that students needed to learn through videos, collaborating with one another or by simply making mistakes. However, the disadvantage of this is that students often missed out on understanding theoretical constructs, such as design techniques, game mechanics, game plan, gamification strategy and other ethical considerations. For example, students often felt lost, did not know where to start, they found building the basic construction to be difficult, among other problems. If students are given a video demonstration on how to plan, design and implement a game within the MinecraftEDU environment, the focus of mechanics and other gamification constructs could have yielded higher quality projects.

\section{Conclusion}

Gamification is a maturing discipline and is applied mostly within the STEM and education disciplines. The results of this study show that gamification can be used in the management discipline, especially in an abstract field such as research methodology. The application of gamification is only limited by our imagination as educators. For gamification to achieve maximum learning, planning needs to take place. Gamification cannot be implemented and assessed without proper planning and knowledge from the educator's perspective. The educator needs to be clear on the goals of the game and the principles that need to be addressed by the game. Attention should be given to aspects such as game economy, game rules and engagement loops. In this research, a broad directive was given without intermediate markers or checkpoints to gauge their progress. If this is not the case, then the entire exercise will be disastrous for the students. They will be frustrated as they do not know what the outcomes are or how to apply the theoretical aspects to gaming principles. The gaming environment is also important. In the case of Minecraft, the educator needs to provide some initial guidance as there are no manuals or tools on how to play the game. This initial guidance assists those students who do not have a gaming affinity.

Teaching research methodology using gamification can become a two-pronged approach. Firstly, a game can be designed to teach research methodology (the focus of this study). This allows for the application of theory in a different way and allows students to engage with the theory of research methodology. Secondly, the research methodology game can be played by students to teach them research methodology (future research). Instead of designing the game, they just play the game.

The performance of the students is improving based on the gamification aspect. What is not known is how this impacts the students' ability to apply the research methodology knowledge in a research project where they are required to perform independent 
research. This will form part of future research. Future research will also focus on the integration of various game elements into a research methodology game.

Let the games continue and be used to teach and empower students to master research methodology and become future researchers.

\section{Acknowledgements}

Not applicable.

\section{Authors' contributions}

CM conceptualised the study and did the data analysis. JC provided insights into gamification conducting the literature review. Both authors read and approved the final manuscript.

\section{Funding}

Not applicable

Availability of data and materials

Not applicable.

\section{Declarations}

Competing interests

Not applicable.

\section{Author details}

${ }^{1}$ Department of Applied Information Systems, University of Johannesburg, Johannesburg, South Africa. ${ }^{2}$ School of Computer Science, College of Engineering and Physical Sciences, University of Birmingham, Birmingham, UK.

Received: 5 May 2021 Accepted: 14 September 2021

Published online: 26 November 2021

\section{References}

Arman, M. S. (2018). Student-centered approach to teaching: it takes two to tango. The Ahfad Journal, 35(2), 64-71. Brathwaite, B., \& Schreiber, I. (2009). Challenges for game designers. Course Technology.

Burke, B. (2014). Gartner redefines gamification. https://blogs.gartner.com/brian_burke/2014/04/04/gartner-redefines-gamif ication/

Caillois, R. (2001). Man, Play, and Games (M. Barash, Trans.). University of Illinois Press

Callaghan, N. (2016). Investigating the role of Minecraft in educational learning environments. Educational Media International, 53(4), 244-260. https://doi.org/10.1080/09523987.2016.1254877

Chetty, J. (2017). Combatting the war against machines: an innovative hands-on approach to coding. In M. S. Khine (Ed.), Robotics in STEM education: redesigning the learning experience (pp. 59-83). Springer International Publishing.

Cohen, E. L. (2014). What makes good games go viral? The role of technology use, efficacy, emotion and enjoyment in players' decision to share a prosocial digital game. Computers in Human Behavior, 33, 321-329. https://doi.org/10.1016/j.chb. 2013.07.013

Cole, H., \& Griffiths, M. D. (2007). Social interactions in massively multiplayer online role-playing gamers. CyberPsychology \& Behavior, 10(4), 575-583. https://doi.org/10.1089/cpb.2007.9988

Dale, S. (2014). Gamification: making work fun, or making fun of work? Business Information Review, 31(2), 82-90. https://doi. org/10.1177/0266382114538350

Deterding, S., Dixon, D., Khaled, R., \& Nacke, L. (2011). From game design elements to gamefulness: defining "gamification". Paper presented at the 15th International Academic MindTrek Conference: Envisioning Future Media Environments. https:// doi.org/10.1145/2181037.2181040

Dichev, C., \& Dicheva, D. (2017). Gamifying education: what is known, what is believed and what remains uncertain: a critical review. International Journal of Educational Technology in Higher Education, 14(1), 1-36. https://doi.org/10.1186/ s41239-017-0042-5

Dicheva, D., Dichev, C., Agre, G., \& Angelova, G. (2015). Gamification in education: a systematic mapping study. Journal of Educational Technology \& Society, 18(3), 75-88.

Ebner, M., \& Holzinger, A. (2007). Successful implementation of user-centered game based learning in higher education: an example from civil engineering. Computers \& Education, 49(3), 873-890. https://doi.org/10.1016/j.compedu.2005.11.026

Ekaputra, G., Lim, C., \& Eng, K. I. (2013). Minecraft: A game as an education and scientific learning tool. Paper presented at the Information Systems International Conference (ISICO)

Ellison, T. L., Evans, J. N., \& Pike, J. (2016). Minecraft, teachers, parents, and learning: what they need to know and understand. School Community Journal, 26(2): 25-44. http://www.schoolcommunitynetwork.org/SCJ.aspx

Felicia, P. (2009). Digital games in schools: a handbook for teachers (C. Kearney Ed.). European Schoolnet.

Flatla, D. R., Gutwin, C., Nacke, L. E., Bateman, S., \& Mandryk, R. L. (2011). Calibration games: making calibration tasks enjoyable by adding motivating game elements. Paper presented at the 24th annual ACM symposium on User interface software and technology. https://doi.org/10.1145/2047196.2047248 
Fuster, H., Chamarro, A., Carbonell, X., \& Vallerand, R. J. (2014). Relationship between passion and motivation for gaming in players of massively multiplayer online role-playing games. Cyberpsychology, Behavior, and Social Networking, 17(5), 292-297. https://doi.org/10.1089/cyber.2013.0349

Gershenfeld, A. (2014). Mind games. Scientific American, 310(2), 54-59.

Han, S., Capraro, R., \& Capraro, M. M. (2015). How science, technology, engineering, and mathematics (STEm) project-based learning (PBL) affects high, middle, and low achievers differently: the impact of student factors on achievement. International Journal of Science and Mathematics Education, 13(5), 1089-1113. https://doi.org/10.1007/s10763-014-9526-0

Hoidn, S. (2017). Introduction. In S. Hoidn (Ed.), Student-centered learning environments in higher education classrooms (pp. 1-21). Palgrave Macmillan US

Hollett, T., \& Ehret, C. (2015). "Bean's World": (Mine) crafting affective atmospheres of gameplay, learning, and care in a children's hospital. New Media \& Society, 17, 1849-1866. https://doi.org/10.1177/1461444814535192

Huotari, K., \& Hamari, J. (2012). Defining gamification: a service marketing perspective. Paper presented at the Proceeding of the 16th International Academic MindTrek Conference. https://doi.org/10.1145/2393132.2393137

Hwang, G.-J., Yin, C., \& Chu, H.-C. (2019). The era of flipped learning: promoting active learning and higher order thinking with innovative flipped learning strategies and supporting systems. Interactive Learning Environments, 27(8), 991-994. https:// doi.org/10.1080/10494820.2019.1667150

Ionica, A. C., \& Leba, M. (2015). Gamification \& research—partnership for innovation. Procedia Economics and Finance, 23, 671-676. https://doi.org/10.1016/S2212-5671(15)00455-4

Jensen, G. H. (2013). Making sense of play in video games: Ludus, Paidia, and possibility spaces. Journal for Computer Game Culture, 7(1), 69-80.

Junco, R. (2014). Beyond 'Screen Time:'What Minecraft Teaches Kids. https://www.theatlantic.com/technology/archive/2014/ 04/beyond-screen-time-what-a-good-game-like-minecraft-teaches-kids/361261/

Juul, J. (2011). Half-real: video games between real rules and fictional worlds. MIT Press.

Kalogiannakis, M., Papadakis, S., \& Zourmpakis, A.-I. (2021). Gamification in science education. A systematic review of the literature. Education Sciences. https://doi.org/10.3390/educsci1 1010022

Kapp, K. M. (2012). The gamification of learning and instruction: game-based methods and strategies for training and education. John Wiley \& Sons.

Kumar, J., \& Herger, M. (2013). Mechanics. In Gamification at work: designing engaging business software: Interaction Design Foundation

Lee, J. J., \& Hammer, J. (2011). Gamification in education: what, how, why bother? Academic Exchange Quarterly, 15(2), $146-151$.

Lewins, A., \& Silver, C. (2008). Using software in qualitative research. Sage Publications.

Minecraft Education Edition. (2021). What is Minecraft? https://education.minecraft.net/en-us/homepage

Mishra, R., \& Kotecha, K. (2015). Defining learning outcomes of co-curricular activities: integrating desired commonalities. Journal of Engineering Education Transformations. https://doi.org/10.16920/jeet/2015/v0i0/59358

O'Neill, G., \& McMahon, T. (2005). Student-centred learning: what does it mean for students and lecturers. In S. Moore, G. O'Neill, \& B. McMullin (Eds.), Emerging issues in the practice of university learning and teaching / (pp. 27-36). Dublin: AISHE.

Reeves, B., \& Read, J. L. (2009). Total engagement: using games and virtual worlds to change the way people work and businesses compete. Harvard Business Press.

Robinson, D., \& Bellotti, V. (2013). A preliminary taxonomy of gamification elements for varying anticipated commitment. Paper presented at the CHI'13: proceedings of the SIGCHI Conference on Human Factors in Computing Systems

Sáez-López, J.-M., Miller, J., Vázquez-Cano, E., \& Domínguez-Garrido, M. C. (2015). Exploring application, attitudes and integration of video games: MinecraftEdu in middle school. Journal of Educational Technology \& Society, 18(3), 114-128.

Sailer, M., Hense, J. U., Mayr, S. K., \& Mandl, H. (2017). How gamification motivates: an experimental study of the effects of specific game design elements on psychological need satisfaction. Computers in Human Behavior, 69, 371-380. https:// doi.org/10.1016/j.chb.2016.12.033

Saldana, J. (2013). The coding manual for qualitative researchers (2nd ed.). SAGE Publications Ltd.

Salen, K., \& Zimmerman, E. (2004). Rules of play: game design fundamentals. MIT Press.

Saunders, M., Lewis, P., \& Thornhill, A. (2016). Research methods for business students (7th ed.). Pearson Education.

Seaborn, K., \& Fels, D. I. (2015). Gamification in theory and action: a survey. International Journal of Human-Computer Studies, 74, 14-31. https://doi.org/10.1016/jijhcs.2014.09.006

Silverman, D. (2017). Doing qualitative research (5th ed.). Sage.

Smeaton, D. (2017). The Minecraft Teacher: an anthropological exploration of the pedagogy behind Minecraft as a teaching tool (pp. 120). https://www.amazon.com/Minecraft-Teacher-anthropological-exploration-pedagogy-ebook/dp/B06X9X61D4

Strayer, J. F. (2012). How learning in an inverted classroom influences cooperation, innovation and task orientation. Learning Environments Research, 15(2), 171-193. https://doi.org/10.1007/s10984-012-9108-4

Streeck, J., Goodwin, C., \& LeBaron, C. (2011). Embodied interaction: language and body in the material world. Cambridge University Press.

Terrill, B. (2008). My coverage of lobby of the social gaming summit. http://www.bretterrill.com/search?q=my+coverage+ of+lobby

Toda, A. M., Oliveira, W., Klock, A. C., Palomino, P. T., Pimenta, M., Gasparini, I., Shi, L., Bittencourt, I., Isotani, S., Cristea, A. I. (2019). A taxonomy of game elements for gamification in educational contexts: proposal and evaluation. Paper presented at the 2019 IEEE 19th International Conference on Advanced Learning Technologies (ICALT)

Trinidad, J. E. (2020). Understanding student-centred learning in higher education: students' and teachers' perceptions, challenges, and cognitive gaps. Journal of Further and Higher Education, 44(8), 1013-1023. https://doi.org/10.1080/0309877X. 2019.1636214

Williamson, B. (2009). Computer games, schools, and young people: a report for educators on using games for learning. Retrieved from Bristol. https://www.nfer.ac.uk/publications/FUTL27/FUTL27.pdf 


\section{Publisher's Note}

Springer Nature remains neutral with regard to jurisdictional claims in published maps and institutional affiliations. 